\title{
A necessária inserção do design na educação básica, integrado à disciplina Artes
}

\author{
The necessary insertion of Design integrated with the discipline of \\ Arts in basic education
}

FRANCO, Annibal Gouvêa

Universidade do Estado de Minas Gerais - UEMG I francoartedesign@gmail.com

CARVALHO, Simone Medeiros de

Universidade Federal de Minas Gerais - UFMG I simone.med@hotmail.com

\begin{abstract}
Resumo
O presente artigo tem por objetivo mapear a presença de conteúdos de arte aplicada, com foco no design, nos currículos de artes do Ensino Fundamental de escolas públicas da RMBH, do 6응 ao 9ano. Também é apresentada a necessária inserção do design na educação básica, integrado à disciplina artes. A metodologia de pesquisa utilizada para a conclusão deste presente estudo foi a pesquisa qualitativa por meio da análise documental. Conclui-se que a abordagem educacional do design é necessária, segundo os PCNs - Parâmetros Curriculares Nacionais (do Brasil) e do CBC - Currículo Básico Comum, em Arte (referente ao Estado de Minas Gerais). A educação, por meio do design, dentre os diversos benefícios proporcionados ao estudante, auxilia-o na compreensão da cultura industrial brasileira.

\section{Abstract}

This paper aims to map the presence of applied arts content - focused on design - in the arts curriculum of elementary public schools in Belo Horizonte, from 6th to 9th grades. The study also supports the necessary insertion of design in basic education, integrated with the arts discipline. Research methodologies applied were the bibliographic research and the qualitative research through documentary analysis. It is concluded that the educational approach of design is important and necessary, according to the PCNs - (Brazilian) National Curricular Parameters - and CBC Common Basic Curriculum in Arts - (referring to the state of Minas Gerais). The education through design, among the various benefits provided to the students, helps them understand the Brazilian industrial culture.
\end{abstract}

Palavras-chave: Currículo. Design. Educação.

Keywords: Curriculum. Design. Education. 


\section{INTRODUC̣ÃO}

Sabe-se que as artes visuais e o design estão correlacionados, pois a arte visual e o design atuam na representação visual de cores e formas; além do seu envolvimento com o segmento artístico, também exercem papel comercial, fundamental na representação gráfica de empresas e instituições públicas.

A arte visual lida com o caráter teórico e prático do estético, abrangendo o desenho, a gravura, a fotografia, o cinema, a escultura, a arquitetura, a moda, a decoração, o paisagismo e o design. Considerando que toda a arte apreciada pelo olhar é conceituada como arte visual, o design também se integra neste conceito.

Ao buscar as interações da arte com o design, é comum nos depararmos com o termo arte aplicada (ARTES APLICADAS, 2017). Tal expressão remete a modalidades da produção artística que se orientam para o mundo cotidiano, pela criação de objetos, de peças e/ou construções úteis ao homem em sua vida diária. A noção pode envolver alguns setores da arquitetura, as artes decorativas, o design, as artes gráficas e o mobiliário, entre outros, e traz oposição em relação às belas-artes.

As artes industriais, nomenclatura apresentada por Wilber (1967), são artes aplicadas voltadas para a cultura industrial e se relacionam, conceitualmente, com os primórdios do design. No movimento Arts and Crafts, segundo De Moraes (1997), havia uma proposta da divisão da arte: arte pura e arte aplicada. Também vieram a ser conhecidas como arte maior e arte menor, e ainda, como belas artes e artesanato. Nessa época, os objetos advindos de métodos industriais, dentre outras denominações, eram considerados oriundos da arte industrial.

Bonsiepe (2011) apresenta o design como uma palavra que, inicialmente, associava-se somente às atividades projetuais, muitas vezes, de cunho industrial. A partir da década de noventa, entretanto, a palavra design foi perdendo o seu significado original e adquirindo outras conotações. Se por um lado a palavra tornou-se mais conhecida, benéfica para a sua disseminação, por outro, ela também encontra-se associada ao efêmero, à moda, ao obsoletismo rápido, e à glamourização do mundo dos objetos.

Retomando as artes industriais, segundo o estadunidense Wilber (1967), elas constituem parte essencial da educação geral, e são necessárias na educação de meninos e meninas para facilitar sua vivência em um mundo industrial e tecnológico. Os Estados Unidos, rapidamente, passaram de uma nação agrária com indústria rudimentar e descentralizada, para um país líder

1 Visto em: 15 jun. 2016, no site: http://www.com/artes/arte-visual/. 
em desenvolvimento industrial, no mundo inteiro. Assim, crianças e adultos vivem hoje em um mundo cercado de instrumentos mecânicos que precisam ser compreendidos e utilizados.

Alguns dos objetivos do ensino das artes industriais na educação geral, citados pelo autor, envolvem: desenvolver atividades recreativas e não profissionais, na área do trabalho construtivo; desenvolver bom gosto por bons trabalhos e desenhos, tanto produtos da indústria atual quanto de culturas passadas; ampliar conhecimentos do estudante como consumidor, permitindo que o mesmo saiba, com inteligência, escolher, adquirir, usar e conservar produtos da indústria; proporcionar informações e experiências sobre os processos básicos de várias indústrias possibilitando, assim, ao estudante, uma melhor escolha de sua futura profissão; encorajar expressão criadora; desenvolver relações sociais; aperfeiçoar a capacidade do indivíduo em determinado número de processos industriais básicos; melhorar as normas de segurança no trabalho.

Considerando a correlação entre arte e design supracitada, segundo os Parâmetros Curriculares Nacionais para o Ensino Médio (BRASIL, 2002), é necessária a valorização do trabalho dos profissionais e técnicos das linguagens artísticas, dos profissionais da crítica, da divulgação e circulação dos produtos de arte. É necessária, também, em relação à apreciação de produtos de artes visuais, que essa integre tanto as produções artísticas em geral, quanto as ligadas ao campo da comunicação como, por exemplo, o design.

As Orientações Curriculares para o Ensino Médio, envolvendo: Linguagens, Códigos e suas Tecnologias (BRASIL, 2006), apresentam uma ideia semelhante pois, segundo estas orientações, no ensino de arte, os múltiplos usos das linguagens são possíveis de serem trabalhados, incluindo manifestações artísticas, profissionais e cotidianas. Considerando as manifestações profissionais, são citadas, dentre várias: o jornal, o rádio, a televisão, o cinema, a internet, a publicidade, a arquitetura, o artesanato, a decoração, e o design.

Entretanto, nos Parâmetros Curriculares Nacionais: Arte / Secretaria de Educação Fundamental (BRASIL, 1997), da 1à à 4ạ séries, o design não é diretamente apreciado, apesar de que o desenho industrial (CENTRO DE FORMAÇÃO DE ASSOCIAÇÃO DAS ESCOLAS DE MATOSINHOS, 2018) (termo diretamente relacionado ao design) é citado como integrante das artes visuais. Ele também é citado como objeto de apreciação significativa, mas não integra o fazer artístico. 
Enquanto no desenho industrial, o profissional é responsável pela elaboração de desenhos e croquis que irão possibilitar o desenvolvimento (design) de novos produtos, por outro lado, o ensino das artes industriais, como visto em Wilber (1967), não tem caráter profissional.

De acordo com Portugal (2013), embora existam no Brasil experiências voltadas para o Ensino Fundamental e Médio, utilizando o Design como fio condutor, muito poucas delas se encontram documentadas e disponíveis para consulta. Considerando o fato de que o design se integra às artes visuais, cuja inserção é necessária ao ensino (visto em Linguagens, Códigos e Tecnologias), Portugal (2013) enuncia que o alfabetismo visual tem sido um tema de interesse recente no meio escolar, e defende que esse é o momento para que surjam experimentos que permeiem as áreas citadas (artes visuais, design e educação).

\section{METODOLOGIA}

A pesquisa qualitativa é definida por Martins (2004), como: “[...] aquela que privilegia a análise de microprocessos, através do estudo das ações sociais individuais e grupais, realizando um exame intensivo dos dados, e caracterizada pela heterodoxia no momento da análise". (MARTINS, 2004, p. 289)

Para o desenvolvimento deste presente trabalho, utiliza-se a pesquisa qualitativa, por meio da técnica da análise documental, que engloba as proposições curriculares da RMBH e os PCN's, do $6^{\circ}$ ao $99^{\circ}$ ano.

Segundo Ludke e André (1986), esta técnica busca identificar informações factuais nos documentos a partir de questões ou hipóteses de interesse. Por meio desta análise, será mapeada a presença de conteúdos de arte aplicada, com foco no design.

A análise de conteúdo é um conjunto de técnicas, com o objetivo de descrever o conteúdo emitido em um determinado processo de comunicação, seja ele por meio de falas ou textos. Desta forma, ela é composta por procedimentos sistemáticos, que proporcionam o levantamento de parâmetros, que permitem a realização da indução de conhecimentos. (BARDIN, 1977; CAVALCANTE; CALIXTO; PINHEIRO, 2014)

Este trabalho, face ao exposto, tem por objetivo mapear a presença de conteúdos de arte aplicada, com foco no design, nos currículos de artes do Ensino Fundamental de escolas públicas da RMBH, do 6으 ao 9ano. 


\section{REFERENCIAL TEÓRICO}

\subsection{A Arte Industrial e o Design na Educação}

Ragan, Stendler e Cabral (1964) afirma que para que a disciplina artes seja funcional, a mesma deve ser utilizada em todas as matérias escolares. Ele defende que o currículo de arte, além de se relacionar com todas as outras disciplinas, está cada vez mais relacionado com a vida da comunidade. Os pais e os cidadão interessados são convidados à visitarem as aulas de arte, e virem para a escola, tanto para verem as exposições dos trabalhos dos alunos, quanto para trazerem exemplares de sua criação artística ou artesanal para mostrar. Em contrapartida, a fim de obter ideias para a expressão através da arte, as crianças são estimuladas à observação em casa e em sua comunidade.

O autor também apresenta a importância das artes industriais na escola primária, pois o seu estudo auxilia o estudante na compreensão dos fundamentos sob os quais a nossa cultura e a de outros países foram construídas, onde a compreensão da cultura industrial ocorre por meio da arte. As artes industriais na escola primária tratam dos processos utilizados para a modificação dos materiais, permitindo a compreensão de como as matérias primas são transformadas em produtos. Elas suplementam e envolvem muitas áreas do currículo da escola primária, principalmente as belas artes e os estudos sociais.

Wilber (1967), autor supracitado que defende o ensino das artes industriais como parte essencial da educação geral, apresenta alguns dos objetivos do ensino desta disciplina, e são eles: desenvolver atividades recreativas e não profissionais, na área do trabalho construtivo; desenvolver bom gosto por bons trabalhos e desenhos, tanto produtos da indústria atual quanto de culturas passadas; ampliar conhecimentos do estudante como consumidor, permitindo que o mesmo saiba, com inteligência, escolher, adquirir, usar e conservar produtos da indústria; proporcionar informações e experiências sobre os processos básicos de várias indústrias possibilitando, assim, ao estudante, uma melhor escolha de sua futura profissão; encorajar expressão criadora; desenvolver relações sociais; aperfeiçoar a capacidade do indivíduo em determinado número de processos industriais básicos; melhorar as normas de segurança no trabalho.

O autor também defende a importância do relacionamento com a comunidade e obtenção de recursos através dela, impondo a necessidade do conhecimento sobre os elementos disponíveis, onde se encontram e como podem ser conseguidos e utilizados. No levantamento de recursos disponíveis, em qualquer comunidade, geralmente descobre-se muito material que pode ser 
usado nas classes das artes industriais e que não é encontrado em outras fontes. Assim, cita-se também a obtenção de matéria prima local, supervisionada por uma pessoa capacitada.

\subsection{O Currículo no Brasil}

No Brasil, após o golpe militar de 1964, segundo Moreira (1997), acordos foram assinados com os Estados Unidos com o objetivo de modernizar e racionalizar o país. Assim, a tendência tecnicista passou a prevalecer nas escolas, contribuindo com o crescimento industrial.

Ainda segundo o autor, a disciplina "currículos e programas" (CP) foi introduzida no curso de pedagogia em 1962, como eletiva. Entretanto, foi na década de 70 que surgiram os primeiros mestrados em currículo, e pode-se afirmar que este campo do saber adquiriu sua maturidade nesta década.

Alguns estudos sobre currículo, realizados a partir das décadas de 60 e 70, apresentam a existência de três níveis: formal, real e oculto. Tais níveis permitem analisar o aprendizado do aluno, acerca de quanto ele aprendeu ou deixou de aprender. (JESUS, 2008; KELLY, 1981).

O currículo formal, oficial, ou prescrito, é indicado pelo que está determinado no papel, estabelecido pelos sistemas de ensino; ele é expresso em diretrizes curriculares, objetivos e conteúdos presentes em uma determinada disciplina ou área de estudo. O currículo real é o que realmente ocorre na prática, ou seja, o que acontece dentro da sala de aula, em decorrência de um projeto pedagógico e dos planos de ensino. O currículo oculto tem este nome por não estar presente no planejamento dos professores, sendo reflexo do modo pelo qual o trabalho da escola é planejado e organizado, envolvendo também as relações sociais; ele engloba tudo o que os alunos aprendem diariamente em meio às várias práticas, atitudes, comportamentos, gestos, percepções, que vigoram no meio social e escolar. (JESUS, 2008; KELLY, 1981).

\subsection{O Design no Currículo Prescrito}

No âmbito do ensino fundamental brasileiro, como apresentado nos Parâmetros Curriculares Nacionais: Arte / Secretaria de Educação Fundamental (BRASIL, 1998), o design faz-se presente da 5a à 8a séries, atualmente, 6ㅇo ao 9 ano. O design é citado, tanto na produção do aluno em artes visuais, quanto na apreciação destas artes, através do conhecimento e competência de leitura das formas visuais, em diversos meios de comunicação da imagem (incluindo o design). 
No Distrito do Porto, em Portugal, segundo o Centro de Formação de Associação das Escolas de Matosinhos, o CNEB5 (Currículo Nacional do Ensino Básico), Portugal (2001), o design é compreendido como conteúdo de educação artística. Nos conteúdos de desenho, o design é apresentado tanto como base para a criação artística, como também para a compreensão de projetos, incluindo a utilização de instrumentos, como compasso e escalímetro, e a aplicação de convenções, como cotas e escalas; também estão inclusas noções de ergonomia e antropometria.

Consta também em Portugal (2001), no CNEB, na educação tecnológica, o design e conceitos de ecodesign. Em tipologia e natureza das atividades tecnológicas, o design está incluso como atividade e, no domínio dos sistemas tecnológicos, há conceitos de ecodesign. No domínio dos sistemas tecnológicos, as competências tecnológicas a serem desenvolvidas pelos alunos, que englobam conceitos do ecodesign, incluem conhecimentos como a análise do ciclo de vida de um objeto e, a análise das relações do objeto nos sistemas técnico, produtivo e ambiental.

Quadrado (2012), autora portuguesa, apresenta uma pesquisa de como um professor de artes visuais pode tornar a sua prática pedagógica, dentre outros aspectos, mais holística. A autora reflete sobre o percurso de aprendizagem da prática de ensino supervisionada, realizada no 3 Ciclo do Ensino Básico, na Escola Secundária Quinta das Palmeiras, na cidade da Covilhã.

O Grupo Disciplinar de Artes Visuais da Escola Secundária Quinta das Palmeiras, inspirado no CNEBEA (Currículo Nacional do Ensino Básico de Educação Artística), realizou, para o ano letivo de 2011/2012, um Plano de Organização do Ensino-Aprendizagem para a Disciplina de Arte e Design. Em design, foram abordados os seguintes conteúdos: conceitos básicos; o problema; o projeto; a criação/originalidade; a prática-aplicação; a amostragem; a divulgação.

Considerando as possíveis atividades de design aplicadas na educação básica, Bertoldi et al. (2011) utilizaram o método "Card Analysing", para identificar tais atividades neste meio. Os autores ressaltaram a importância das habilidades relacionadas ao processo de design para todos os cidadãos, no contexto da sociedade criativa. Por meio do método supracitado, as habilidades relacionadas ao design (vide Figura 1), nas escolas estudadas, tiveram a sua presença constatada; entretanto, foi observado que o seu desenvolvimento ocorreu de maneira inconsciente na maioria dos casos, tanto pelos professores, quanto pelos alunos. 
Figura 1 - Resultados obtidos, considerando as principais habilidades observadas pelos alunos.

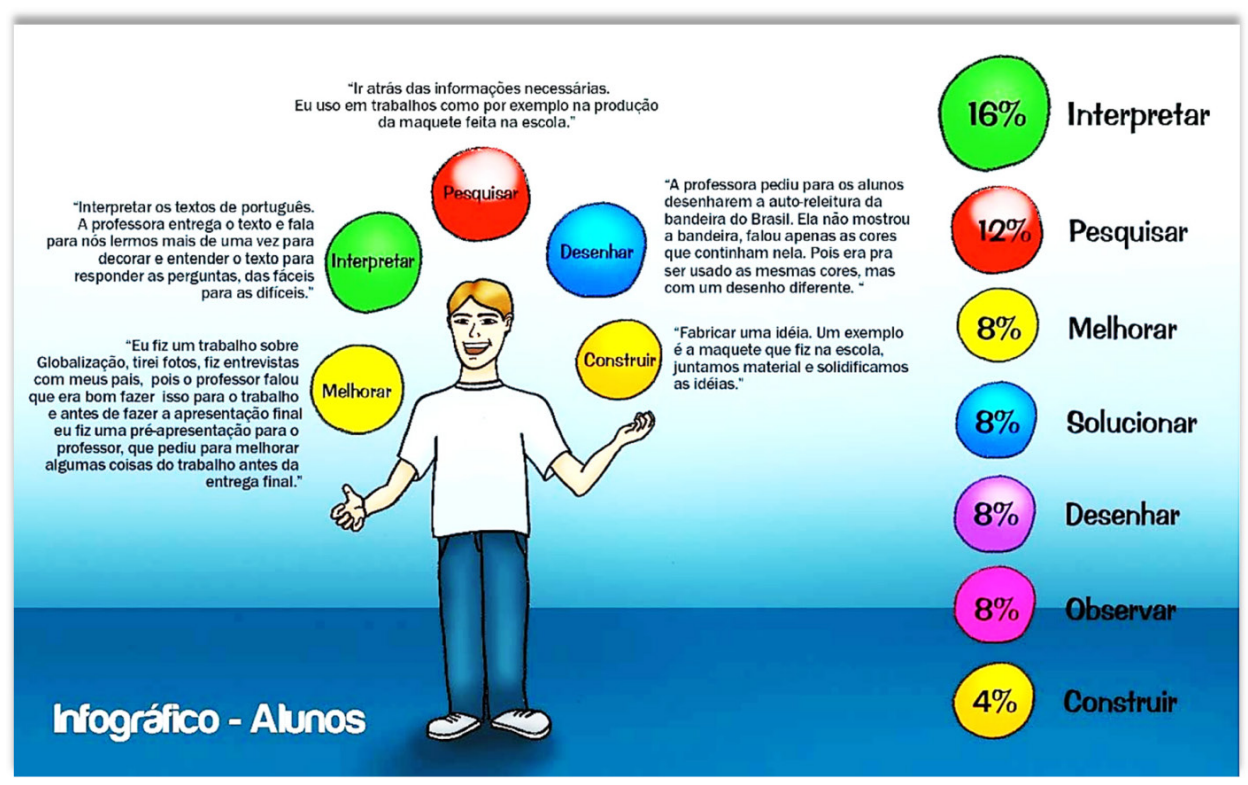

Fonte: Bertoldi et al. (2013, p. 23).

Percebeu-se que as habilidades relacionadas ao design são estimuladas pelos professores, que por meio das tarefas escolares, propõem atividades de design indiretamente. Em sua totalidade, foram pesquisadas as seguintes habilidades relacionadas ao design: "adaptar", "analisar", "aplicar", "combinar", "comparar", "conceituar", "construir", "criar", "desenhar", "estruturar", "interpretar", "melhorar", "observar", "pesquisar", "planejar", "projetar", "prototipar", "refletir", "relatar" e "solucionar". Como exemplo, cita-se que um estudante, ao elaborar uma maquete, relatou que precisou pesquisar as informações para o entendimento do tema e utilizar um desenho como guia na construção da mesma.

\subsection{A Educação pelo Design}

Fontoura (2002) pesquisou a educação de crianças por meio de atividades de design, considerando o seu potencial pedagógico. Ele defende a proposta EdaDe - Educação através do Design e enfatiza a necessidade do desenvolvimento um "modelo" brasileiro. Tal proposição foi embasada na pedagogia da ação revisada e no construtivismo.

Para uma melhor contextualização, a supracitada pedagogia construtivista, segundo Arias e Yera (2012), não surgiu como uma teoria pedagógica, pois trata-se de uma concepção filosófico-psicológica sobre o desenvolvimento mental do homem e, em particular, das crianças. No âmbito da educação escolar, o construtivismo compreende a aprendizagem como um processo de construção de conhecimentos, e a sua elaboração ocorre mutuamente entre as crianças e os adultos (professores), por meio do diálogo, 
mas o epicentro desse processo é a própria criança. A aprendizagem não mais reside na figura do professor e, logo, a pedagogia deve centrar-se mais no aprendizado do que no ensino.

O autor difere o construtivismo do behaviorismo. Segundo Arias e Yera (2012), o construtivismo,

[...] defende a idéia de que as pessoas nascem apenas com um conjunto de predisposições neuro-fisiológicas para o pensar que precisam ser desenvolvidas no percurso da vida. Por isso as estruturas mentais devem ser concebidas como o produto de uma construção realizada pela criança em prolongadas etapas de reflexão individual e de interação com o outro (ARIAS; YERA, 2012, p. 12).

Ainda segundo o autor, o behaviorismo, ao contrário do construtivismo, considera a imposição das estruturas mentais externas às crianças, e postula que os processos de aprendizagem são advindos do biologismo e dos estímulos ambientais.

Para falar da pedagogia da ação, supracitada, é necessário apresentar a Bauhaus. Segundo Fontoura (2001), a "Staatliche Bauhaus" foi fundada por Walter GROPIUS em 1919, na Alemanha, e permitiu experiências pedagógicas no domínio das artes, do artesanato, do design e da arquitetura. Ela ultrapassou as suas dimensões físicas como escola, e se transformou em um movimento cultural e artístico internacional.

Ribeiro e Lourenço (2015) apresentam o Manifesto Bauhaus, que esboçava o seu programa pedagógico. Segundo as autoras,

Gropius, no Manifesto Bauhaus, esboçou o que seria o programa pedagógico desta escola: um ensino da arte, com o intuito de unificar o trabalho do artista, do artesão e da indústria para assim ajudar a Alemanha a se reerguer economicamente. Propunha-se transformar os artistas livres, sem "função social", em um ser produtivo para a sociedade (segundo parágrafo do Manifesto Bauhaus). (RIBEIRO; LOURENÇO, 2015, p. 9).

A pedagogia "bauhauseana", associada à prática da pedagogia da ação por Fontoura (2001), promovia uma discussão e revisão do panorama da educação geral e, principalmente, do ensino das artes daquele século. Em sua concepção, ela parte do princípio de que o aprendizado se dá a partir do próprio educando, rejeitando a ideia de que o ensino se faz através de uma suposta transmissão de conhecimentos. Por meio desta ótica, o aprendizado visa a auto formação do educando. O programa pedagógico proposto visava o estímulo 
criativo por meio da prática manual e artística, permitindo assim, ao estudante, o desenvolvimento de uma personalidade ativa, espontânea e sem inibições.

Entretanto, Wick (1989) afirma que, conceber uma pedagogia da Bauhaus é inadmissível pois, tal pedagogia tem se tornado sinônimo do nome Johannes Itten, por meio de utilização seletiva de aspectos isolados da supracitada pedagogia "bauhauseana" no ensino da arte nas escolas. Em seu livro, o autor explora os múltiplos aspectos da pedagogia da Bauhaus visando a formação do artista e do designer e, analisa se a prática pedagógica de alguns dos mestres da Bauhaus contribuiu para a concretização dos objetivos da Bauhaus.

Ao citar uma pedagogia, por meio da arte e do design, também cabe citar o pensamento pelo design, conhecido como "design thinking". Segundo Brown (2010), essa maneira de pensar tem como finalidade dar ferramentas às pessoas que talvez nunca tenham pensado em si mesmas como designers, de forma a aplicá-las em uma ampla variedade de problemas.

Ainda segundo Brown (2010), o "design thinking" beneficia a nossa intrínseca capacidade criativa, normalmente negligenciada por práticas mais convencionais na resolução de problemas, nas mais diversas áreas. Tal ferramenta pode ser utilizada até mesmo na gestão e, atualmente, não é incomum encontrar designers nos conselhos de administração de algumas empresas progressistas.

Tal fato pode ser confirmado em Gorb (1990), através do "design management". Essa metodologia, assim com o "design thinking", também é utilizada para a solução de problemas, entretanto, em especial, no âmbito empresarial, por meio da seleção das ferramentas de design necessárias para a solução dos mesmos. Dessa forma, os gestores são treinados para utilizar o design de maneira eficaz.

Uma análise das características e conceitos fundamentais do design e da gestão, revela mais semelhanças do que diferenças, segundo Mozota, Klopsch e Campelo (2011). A autora compara conceitos-chave de design e gestão, e demonstra que a grande maioria deles é comum em ambas as áreas.

Ainda segundo Mozota, Klopsch e Campelo (2011), como um processo criativo, o design segue diferentes fases. Por meio da identificação de um problema, o designer segue um processo lógico (Figura 2), mediante a utilização de técnicas e habilidades aprendidas, e não pela utilização de talentos ou mero acaso. Relembrando o supracitado Bertoldi et al. (2011), quanto as habilidades relacionadas ao design, pode-se inferir a presença delas na Figura 2, pois elas são necessárias para o processo de design. Logo, o supracitado estudante, que ao elaborar uma maquete, relatou precisar pesquisar as informações para o entendimento do tema e utilizar um desenho como guia na construção 
da mesma, utilizou, mesmo que intuitivamente (BERTOLDI et al., 2011), contrariando Mozota, Klopsch e Campelo (2011), o processo de design para a execução do seu trabalho.

Figura 2 - O processo de design.

\begin{tabular}{|c|c|c|}
\hline ETAPAS & OBJETIVO & RESULTADOS VISUAIS \\
\hline 0. Investigação & Ideia & Reunião \\
\hline 1. Pesquisa & Conceito & Conceito visual \\
\hline 2. Exploração & Escolha de estilo & $\begin{array}{c}\text { Esboços de ideias, rascunhos } \\
\text { Esboços de apresentação } \\
\text { Modelo em escala reduzida }\end{array}$ \\
\hline 3. Desenvolvimento & Protótipo & $\begin{array}{c}\text { Desenhos técnicos } \\
\text { Modelo funcional }\end{array}$ \\
\hline 4. Realização & Tetalhamento & $\begin{array}{c}\text { Simulação 3D para correção visual } \\
\text { Capacidades de funcionamento }\end{array}$ \\
\hline 5. Avaliação & Produção & $\begin{array}{c}\text { Documentos de execução } \\
\text { Protótipo }\end{array}$ \\
\hline
\end{tabular}

Fonte: Mozota, Klopsch e Campelo (2011, p. 27).

Retomando Fontoura (2002), por meio do design, o processo de ensinoaprendizagem se torna mais dinâmico. As atividades de design promovem a estimulação sensório-motora, pois as crianças e jovens manipulam objetos, materiais, ferramentas, equipamentos e máquinas; constróem modelos, maquetes e protótipos; ao mesmo tempo, pensam e refletem sobre as suas ações. O pensamento é integrado à ação.

Ainda segundo o autor, a EdaDe - educação através do design promove o aprendizado significativo, ligado às coisas da vida, promove a interdisciplinaridade e permite a construção do conhecimento através do ensino e do aprendizado ativo, tanto por parte do aluno, quanto do professor, mesmo lembrando que esta maneira de educar é caracterizada como centrada no aluno, como em suas raízes construtivistas. $\mathrm{Na}$ EdaDe, o professor é um promotor de experiências e vivências, e ele auxilia ativamente no processo de construção de conhecimentos em sala de aula.

\section{ANÁLISE DE DADOS}

No âmbito do ensino fundamental, supracitado por meio dos Parâmetros Curriculares Nacionais: Arte / Secretaria de Educação Fundamental (BRASIL,


O design é citado, tanto na produção do aluno em artes visuais, quanto na apreciação destas artes, através do conhecimento e competência de leitura das formas visuais, em diversos meios de comunicação da imagem (incluindo o design). 
Em um link para o website do Centro de Referência Virtual do Professor², é apresentada a Proposta Curricular - CBC (Currículo Básico Comum) em Arte 3 , do Ensino Fundamental, do 6음 ao ano, referente ao estado de Minas Gerais. Segundo a proposta, é essencial o conhecimento dos diversos instrumentos de produção artística, como um meio para que se consiga ver, significar e produzir a arte. Além das formas tradicionais de arte, as modalidades que resultam nos avanços tecnológicos e transformações estéticas do século XX, também devem ser abordadas; dentre elas, é citado o design.

Ainda no currículo prescrito para o ensino fundamental, segundo as Proposições Curriculares em Arte para o Ensino Fundamental, da Rede Municipal de Educação de Belo Horizonte (BELO HORIZONTE, 2010), o design, ou mesmo, as artes aplicadas, não se fazem presentes; tal afirmação pode ser confirmada por meio da análise do currículo do primeiro, segundo e terceiro ciclos. No sistema de ciclos, o período do 6ำ ao 9a ano, cuja análise foi proposta na metodologia, equivale-se ao $3^{\circ}$ ano do segundo ciclo e do $1^{\circ}$ ao 3 을 ano do terceiro ciclo, presentes nas proposições curriculares da $\mathrm{RMBH}$.

Apesar de que o currículo prescrito para o ensino fundamental, segundo as Proposições Curriculares em Arte para o Ensino Fundamental, da Rede Municipal de Educação de Belo Horizonte (BELO HORIZONTE, 2010), não está sendo cumprido em relação à existência de um conteúdo específico envolvendo o design, ou mesmo as artes aplicadas, foi feita uma análise em busca de habilidades relacionadas ao design. Estas habilidades, supracitadas em Bertoldi et al. (2011), foram investigadas nas Proposições Curriculares em Arte para o Ensino Fundamental da RMBH.

Mediante a análise das Proposições Curriculares em Arte para o Ensino Fundamental, da Rede Municipal de Educação de Belo Horizonte (BELO HORIZONTE, 2010), as seguintes habilidades relacionadas ao design, supracitadas em Bertoldi et al. (2011), foram investigadas: "adaptar", "analisar", "aplicar", "combinar", "comparar", "conceituar", "construir", "criar", "desenhar", "estruturar", "interpretar", "melhorar", "observar", "pesquisar", "planejar", "projetar", "prototipar", "refletir", "relatar" e "solucionar". No 2o ciclo do ensino fundamental, que é constituído pelo $4^{\circ}$ ao 6 ano, as supracitadas habilidades não foram encontradas. Entretanto, no 30 ciclo do ensino fundamental, que é constituído pelo 7음o 9o ano, as habilidades "refletir" e "desenhar" (desenho de observação), foram encontradas.

2 Visto em: 20 set. 2016, no site:

http://crv.educacao.mg.gov.br/sistema_crv/index.aspx?\&usr=pub\&id_ projeto $=27 \&$ id_objeto $=38680 \& i d_{-}$pai $=38679 \&$ tipo $=\operatorname{txg} \& n 1=\& n 2=$ Proposta $\% 20$ Curricular \% $20-\% 20$ C B C \& n $3=$ Fundamental $\% 20-\% 206^{\circ} \% 20$ a o \% 20 9&n4=Arte\&b=s\&ordem =campo3\&cp=fc5e36\&cb=mar. $a$

3 Visto em: 20 set. 2016 no site: http://crv.educacao.mg.gov.br/sistema_crv/banco_ objetos_crv/\%7BE9F7E455-BC41-480C-BB41-6BC032BE8999\%7D_livro\%20de\%20artes.pdf 


\section{CONSIDERAC̣ÕES FINAIS}

A abordagem educacional do design, dentre os diversos benefícios proporcionados ao estudante, auxilia-o na compreensão da cultura industrial brasileira. Tal cultura registrou grande expressividade após o golpe militar de 64, com a modernização e racionalização do país e, o incentivo à educação tecnicista.

No âmbito do ensino fundamental, o design faz-se presente do 60 ao 90 ano; tal fato pode ser confirmado por meio da análise dos PCNs - Parâmetros Curriculares Nacionais (do Brasil) e do CBC - Currículo Básico Comum, em Arte (referente ao Estado de Minas Gerais). Cabe relembrar que o estudo do design permeia, desde as artes plásticas, até os estudos sociais, denotando assim a sua multidisciplinaridade. Apesar da importância dada à inserção do design nos PCNs e no CBC, entretanto, esta não está explícita no currículo prescrito para o referido ensino, segundo as Proposições Curriculares em Arte para o Ensino Fundamental da RMBH - Rede Municipal de Educação de Belo Horizonte.

A correção de tal equívoco dar-se-á, certamente, por meio da imprescindível inserção do design à disciplina artes, na $\mathrm{RMBH}$, dentro da urgência cabível.

\section{REFERÊNCIAS}

ARIAS, José O. Cardentey; YERA, Armando Pérez. O que é a pedagogia construtivista? Revista de Educação Pública, Cuiabá, v. 5, n. 8, p. 11-22, 2012.

ARTES APLICADAS. In: Enciclopédia Itaú Cultural. 2017.

Disponível em: <http://enciclopedia.itaucultural.org.br/termo908/ artes\%E2\%80\%90aplicadas>. Acesso em: 5 maio 2018.

BARDIN, Laurence. Análise de conteúdo. Tradução de Luís Antero Neto e Augusto Pinheiro. Lisboa: Ed. 70, 1977.

BELO HORIZONTE. Secretaria Municipal de Educação. Proposições curriculares: arte. Belo Horizonte, 2010.

BERTOLDI, Aline Dayanna et al. Identificando atividades de design na educação básica por meio do método Card Analysing. InfoDesign: Revista Brasileira de Design da Informação, São Paulo, v. 8, n. 3, p. 20-25, 2011.

BONSIEPE, Gui. Design, cultura e sociedade. São Paulo: Blucher, 2011.

BRASIL. Ministério da Educação. Secretaria de Educação Básica. Orientações curriculares para o ensino médio: linguagens, códigos e suas tecnologias. Brasília, 2006. 
BRASIL. Ministério da Educação. Secretaria de Educação Média e Tecnológica. Parâmetros curriculares nacionais: ensino médio. Brasília, 2002.

BRASIL. Secretaria de Educação Fundamental. Parâmetros curriculares nacionais: arte. Brasília, 1997.

BRASIL. Secretaria de Educação Fundamental. Parâmetros curriculares nacionais: arte. Brasília, 1998.

BROWN, Tim. Design thinking: uma metodologia poderosa para decretar o fim das velhas ideias. Rio de Janeiro: Elsevier, 2010.

CAVALCANTE, Ricardo Bezerra; CALIXTO, Pedro; PINHEIRO, Marta Macedo Kerr. Análise de conteúdo: considerações gerais, relações com a pergunta de pesquisa, possibilidades e limitações do método. Informação \& Sociedade: Estudos, João Pessoa, v. 24, n. 1, p. 13-18, jan./abr. 2014.

\section{CENTRO DE FORMAÇÃO DE ASSOCIAÇÃO DAS ESCOLAS DE}

MATOSINHOS. Disponível em: <https://www.cfaematosinhos.eu/>. Acesso em: 5 maio 2018.

DE MORAES, Dijon. Limites do design. São Paulo: Studio Nobel, 1997.

FONTOURA, Antônio Martiniano. EdaDe: educação de crianças e jovens através do design. 2002. 354 f. Tese (Doutorado em Engenharia de Produção) - Universidade Federal de Santa Catarina, Florianópolis, 2002.

FONTOURA, Antônio. Bauhaus: a pedagogia da ação. ABC Design: Revista Design do Paraná, Curitiba, v. 1, n. 1, p. 32-37, 2001.

GORB, Peter (Ed.). Design management: papers from the London Business School. New York: N. Reinhold, 1990.

JESUS, Adriana Regina de. Currículo e educação: conceito e questões no contexto educacional. In: CONGRESSO NACIONAL DE EDUCAÇÃO, 2008, Lagarto. Anais... Lagarto, 2008. Disponível em: <http://lagarto.ufs.br/uploads/ content_attach/path/11339/curriculo_e_educacao_0.pdf $>$. Acesso em: 5 maio 2018.

KELLY, Albert Victor. O currículo: teoria e prática. São Paulo: Harbra, 1981.

LUDKE, Menga; ANDRÉ, Marli Eliza D. A. Pesquisa em educação: abordagens qualitativas. São Paulo: Ed. EPU, 1986.

MARTINS, Heloisa Helena T de Souza. Metodologia qualitativa de pesquisa. Educação e Pesquisa, São Paulo, v. 30, n. 2, p. 289-300, 2004.

MOREIRA, Antônio Flávio Barbosa. Currículos e programas no Brasil. Campinas: Papirus, 1997.

MOZOTA, Brigitte Borja de; KLOPSCH, Cássia; CAMPELO, Felipe. Gestão do design: usando o design para construir valor de marca e inovação corporativa. Porto Alegre: Bookman, 2011. 
PORTUGAL, Cristina. Design, educação e tecnologia. Rio de Janeiro: Rio Books, 2013.

PORTUGAL. Ministério da Educação. Currículo nacional do ensino básico: competências essenciais. Porto, 2001.

QUADRADO, Ana Cristina Gonçalves. Prática de ensino supervisionada: arte e design, 8 ano: educação expressiva, as artes visuais para além de si. 2012. 93 f. Tese (Doutorado) - Universidade da Beira Interior, Covilhã, 2012.

RAGAN, William B.; STENDLER, Celia Burns; CABRAL, Ruth. Currículo primário moderno. Porto Alegre: Globo, 1964.

RIBEIRO, Sônia Marques Antunes; LOURENÇO, Carolina Amorim. Bauhaus: uma pedagogia para o design. Estudos em Design, Rio de Janeiro, v. 20, n. 1, 2015.

WICK, Rainer. Pedagogia da Bauhaus. São Paulo: M. Fontes, 1989.

WILBER, Gordon Owen. Artes industriais na educação geral. Tradução de Virgílio Cavalcanti. 2. ed. Rio de Janeiro: F. Bastos, 1967.

Data de submissão: 29-09-2016

Data de aceite: 20-06-2018 